Research brief

\title{
Vasoactive intestinal peptide reduces the inflammatory profile in mice infected with Trypanosoma cruzi
}

\author{
Pulchéria Maria Silva Higyno a , Priscila Fagundes Mendes a , Marina Barcelos de Miranda a, \\ Dario Elias Pereira a , Ana Paula Lucas Mota ' , Katiane de Oliveira Pinto Coelho Nogueira a , \\ Ivo Santana Caldas ${ }^{\mathrm{a}, \mathrm{b}}$, Sandra Aparecida de Lima Moura ${ }^{\mathrm{a}}$, \\ Cristiane Alves da Silva Menezes ${ }^{\text {c, * }}$ \\ a Instituto de Ciências Exatas e Biológicas, Departamento de Ciências Biológicas, Universidade Federal de Ouro Preto, Campus Morro do Cruzeiro S/N, \\ Ouro Preto, Minas Gerais, CEP: 35400-000, Brazil \\ ${ }^{\mathrm{b}}$ Departamento de Patologia e Parasitologia, Universidade Federal de Alfenas, Rua Gabriel Monteiro da Silva, 700, Alfenas, Minas Gerais, CEP: 37130-000, \\ Brazil \\ ${ }^{\text {c } F a c u l d a d e ~ d e ~ F a r m a ́ c i a, ~ D e p a r t a m e n t o ~ d e ~ A n a ́ l i s e s ~ C l i ́ n i c a s ~ e ~ T o x i c o l o ́ g i c a s, ~ U n i v e r s i d a d e ~ F e d e r a l ~ d e ~ M i n a s ~ G e r a i s, ~ A v e n i d a ~ P r e s i d e n t e ~ A n t o ̂ n i o ~ C a r l o s, ~}$ \\ 6627, Belo Horizonte, Minas Gerais, CEP: 31270-901, Brazil
}

\section{H I G H L I G H T S}

- The effect of VIP treatment on mice infected with $T$. cruzi was studied.

- VIP treatment had no impact on parasitemia.

- VIP treatment reduced heart mass and heart inflammatory infiltrates.

- VIP treatment reduced levels of IFNgamma and IL-2 and increased IL-4 levels.

- VIP treatment effects may be due to the switch from a Th1 to a Th2 profile.

\section{A R T I C L E I N F O}

\section{Article history:}

Received 29 October 2014

Received in revised form

23 July 2015

Accepted 3 September 2015

Available online 7 September 2015

\section{Keywords:}

Trypanosoma cruzi

vasoactive intestinal peptide

Neuroimmunomodulation
G R A P H I C A L A B S T R A C T

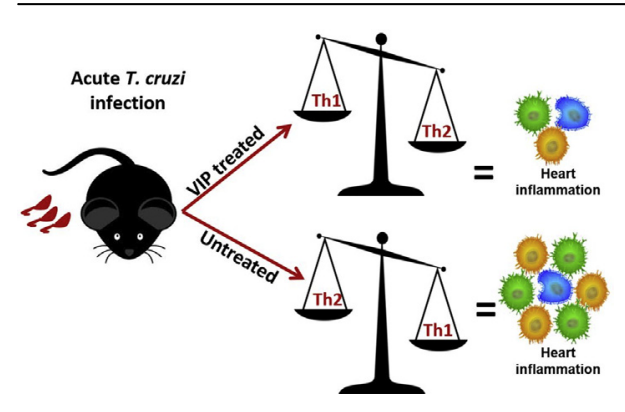

\begin{abstract}
A B S T R A C T
Vasoactive intestinal peptide (VIP) has gained great prominence because of its therapeutic potential, which is ascribed to its ability to regulate innate immunity, inhibit antigen-specific Th1 cell responses, and generate $\mathrm{T}$ regulatory cells. Additionally, VIP may act as a natural antimicrobial peptide, killing bacteria, fungi, and infective forms of Trypanosoma brucei. Despite the possible relevance of VIP during the course of Chagas disease, studies regarding this in human and experimental Trypanosoma cruzi infections remain poorly characterized. In this work, we evaluated the effects of VIP on systemic and cardiac immune responses during experimental acute infection. C57BL/6 mice were infected with 5000 trypomastigotes of the VL-10 strain of T. cruzi and treated with intraperitoneal VIP injection every other day for one month. After 30 days, we observed no reduction in parasitemia levels. However, we observed a reduction in serum levels of IFN-gamma and IL-2 and an increase in that of IL-4. These data suggest that VIP treatment modified immune responses to favor the Th2 response, which had no impact on parasitemia levels although the serum level of IFN-gamma was reduced. However, this change in immune balance reduced heart damage, as noted by the smaller cardiac volume and the moderate inflammatory
\end{abstract}

\footnotetext{
* Corresponding author.

E-mail address: menezescristiane1@gmail.com (C.A.S. Menezes).
} 
infiltrate observed in VIP-treated mice. Our results indicate that VIP treatment reduced the inflammatory response at the cardiac site of mice that were experimentally infected with $T$. cruzi. These data suggest a protective role for VIP in the heart of infected mice.

(c) 2015 Elsevier Inc. All rights reserved.

\section{Introduction}

Trypanosoma cruzi is the causative agent of Chagas disease, which afflicts approximately 8-10 million people in Latin America, making it the most lethal endemic infectious disease in the Western Hemisphere. Parasite transmission frequently occurs through contact with the feces of infected triatomine bugs. However, infection can additionally be transmitted through blood transfusion, organ transplantation, from mother to child, and the consumption of contaminated food and beverages (WHO, 2012).

Chagas disease progression involves two successive stages: an acute phase and a chronic phase. The acute phase is generally asymptomatic and is characterized by the presence of the parasite in blood. The chronic phase is characterized by decreased parasitemia and features four distinct clinical forms: the indeterminate, cardiac, digestive, and cardiodigestive forms. The factors that cause the development of different clinical forms in individuals infected with $T$. cruzi are not completely understood. However, host genetics, the host immune system, and parasite variability are involved in disease evolution (Dutra et al., 2014).

Contact between parasites and host cells is critical in Chagas disease. This contact triggers the initial immune response through cellular activation. However, cellular reactivity is possibly maintained by the antigenic components of the parasite and host. The anti-parasite reactivity, which is essential for chronic disease development, leads to pathology if not properly modulated (Dutra et al., 2009). The identification of endogenous factors that control exacerbated immune responses is a key goal for the development of preventive and therapeutic approaches to infectious and inflammatory diseases.

Neuropeptides play many roles in the immune system. Vasoactive intestinal peptide (VIP) is a neuropeptide comprised of 28 amino acids and exerts immunoregulatory and neuromodulatory effects on various organs and tissues (Igarashi et al., 2011). The biological functions of VIP occur through the binding of the neuropeptide to its two $G$ protein-coupled receptors, VPAC1 and VPAC2. VIP receptors are expressed differentially in immunocompetent cells. The cAMP/PKA pathway is the major signaling pathway for VIP anti-inflammatory action in macrophages, monocytes, DCs, and microglia and in the regulation of $\mathrm{T}$ lymphocyte responses (Corrêa et al., 2013).

VIP-receptor engagement inhibits phagocytic activity, reduces free radical production and adhesion/migration activity, and decreases costimulatory molecule expression (De La Fuente et al., 1996.). Additionally, VIP decreases inflammatory cytokine production and increases anti-inflammatory cytokine production (Delgado et al., 1996, 1999), reduces nitric oxide synthases and cyclooxygenase production, and inhibits toll-like receptor (TLR) expression (Gomariz et al., 2005). With respect to regulatory T cell biology, VIP treatment generates these cells by converting $\mathrm{CD} 4^{+} \mathrm{CD} 25^{-}$cells into $\mathrm{CD} 4^{+} \mathrm{CD} 25^{+}$cells (Anderson and GonzalezRey, 2010).

Recent results in experimental models have demonstrated positive effects of VIP treatment in different pathological conditions where this neuropeptide has emerged as a potent antiinflammatory agent because of its ability to regulate innate immunity by inhibiting Th1 cell responses and generating regulatory T cells (Pozo et al., 2007). In a murine Schistosoma mansoni infection, VIP treatment was very effective in diminishing worm fecundity, hepatic granuloma size and number, and liver collagen content. Serum levels of IL-10 increased, while levels of IL-12 and TNF-alpha decreased, because of VIP administration. In addition, hepatic function improved after VIP administration. These results indicate that the administration of exogenous VIP can be effective in ameliorating immunopathological damage associated with schistosomiasis (Allam, 2007). In addition to their immunomodulatory role, neuropeptides also have antimicrobial activity against a range of microorganisms from skin, oral, respiratory, and gastrointestinal tract sites. VIP possesses direct antimicrobial activities against a range of pathogens, including Escherichia coli, Pseudomonas aeruginosa, Candida albicans, and Streptococcus mutans (El Karim et al., 2008). Additionally, VIP displays strong antimicrobial activity against Trypanosoma brucei, causing parasite death via the destruction of membrane integrity (Gonzalez-Rey et al., 2006). In experimental $T$. brucei infection, VIP treatment improved symptoms in chronic trypanosomiasis by reducing parasite burden in many target organs (Delgado et al., 2009).

Until now, no studies have elucidated the effect of VIP on parasitemia or cardiac inflammation during an experimental T. cruzi infection. Thus, considering that cardiac Chagas disease is characterized by a prominent initial inflammatory response, the aim of this investigation is to evaluate the effects of VIP treatment on parasite persistence and the development of systemic and cardiac inflammation in experimental acute infection induced by VL-10, a cardiotropic strain of T. cruzi (Caldas et al., 2008).

\section{Material and methods}

\subsection{Animal infection and VIP treatment}

Five-to-six-week-old female C57BL/6 mice were obtained from and housed in the animal facility at Universidade Federal de Ouro Preto (UFOP, MG, Brazil) under ad libitum water and feeding conditions. Groups of ten animals were inoculated with the T. cruzi VL10 strain (5000 trypomastigote forms) intraperitoneally. The groups of infected and uninfected mice were then treated with intraperitoneal VIP every other day $(1.5 \mathrm{nmol} / \mathrm{animal}$; American Peptide Company) for 30 days (Delgado et al., 2009). Parasitemia was determined daily for 30 days by using a $5 \mu \mathrm{L}$ blood sample obtained from the tail, according to the Brener protocol (Brener, 1962). Curves were plotted by using the mean parasitemia of ten mice. All experimental protocols described here were approved by the Ethical Committee for Experiments with Laboratory Animals (CEUAUFOP No \#2012/47) and performed in compliance with the guidelines issued by Colégio Brasileiro de Experimentação Animal.

\subsection{Cytokines and chemokine ELISA}

Blood samples from VIP-treated and untreated infected mice were collected from the orbital venous sinus $(0.5 \mathrm{~mL})$ on day 30 post-infection to determine circulating IFN-gamma, IL-2, IL-4, and MIP-2 by ELISA. Briefly, equal volumes of plasma and $1.2 \%$ 
trifluoroacetic acid/1.35 M NaCl were mixed and left for 10 min at $25^{\circ} \mathrm{C}$. The samples were then centrifuged for $5 \mathrm{~min}$ at $3000 \times \mathrm{g}$, and supernatants were adjusted for salt content ( $0.14 \mathrm{M}$ sodium chloride and $0.01 \mathrm{M}$ sodium phosphate) and normalized to $\mathrm{pH} 7.4$ to determine the concentrations of these soluble murine cytokines. IFN-gamma, IL-2, IL-4, and MIP-2 (PeproTech; Brasil FUNPEC) were then quantified by ELISA according to the manufacturer's instructions. All samples were measured simultaneously in duplicate.

\subsection{Heart mass measurement}

Hearts were carefully excised ex vivo and gently blotted on absorbent paper to remove blood before wet weight measurements were calculated. Relative heart weight was calculated using the ratio of heart weight to body weight in milligrams $(\mathrm{mg})$. This value was used to evaluate the cardiac mass obtained after 30 days of infection and after treatment with VIP.

\subsection{Histopathological analysis}

Animals were euthanized on day 30 after $T$. cruzi infection, and ventricular heart tissue was fixed by using $4 \%$ glutaraldehyde in PBS (0.1 M, pH 7.4), dehydrated, and embedded in glycol methacrylate medium (Historesin ${ }^{\underline{B}}$, Leica). Blocks were cut into $2-\mu \mathrm{m}$ sections and stained with hematoxylin and eosin ( $\mathrm{H} \& \mathrm{E})$ for routine histopathological analysis and for the qualitative evaluation of myocardial inflammation and the presence of amastigote nests. Twenty fields from each H\&E-stained section were randomly chosen at a $40 \mathrm{X}$ magnification, resulting in $1.5 \times 10^{6} \mu \mathrm{m}^{2}$ of analyzed myocardial area. Images were obtained using a Leica DM $5000 \mathrm{~B}$ microscope (Leica Application Suite, version 2.4.0 R1) and processed with Leica QWin (version 3) image analyzer software. The inflammatory process was evaluated using the correlation index between the number of cells observed in myocardial muscle of uninfected and infected animals (Caldas et al., 2008)

\subsection{Statistical analysis}

For all experiments, statistical significance was established at $\mathrm{p}<0.05$. Results are presented as the mean \pm SD. All statistical analyses were performed using GraphPad Prism (version 5.0) software. Normal distribution of data was assessed according to
D'Agostino-Pearson analysis. Serological analyses between groups were performed using a t-Test. Parasitemia was analyzed using analysis of variance (ANOVA) followed by the Tukey's post hoc test.

\section{Results}

We first evaluated the effects of VIP treatment on parasitemia in mice infected with the cardiotropic VL-10 strain of T. cruzi. Parasite load in blood smears was monitored daily from day 7 until day 30 after infection. Assessment of parasitemia levels in all animals infected with $T$. cruzi showed that control (infected untreated) animals and VIP-treated animals had similar parasitemia levels (Fig. 1). However, on day 15, VIP-treated animals exhibited a drastic increase in circulating parasites. In subsequent days, parasitemia levels between groups remained similar (Fig. 1).

Considering that proinflammatory cytokine production is important to control initial T. cruzi replication and that VIP has been implicated in modulating the immune system, we evaluated possible alterations in the expression of cytokines (IFN-gamma, IL2, and IL-4) and the chemokine MIP-2 after infection and treatment with VIP. In VIP-untreated mice, infection with $T$. cruzi enhanced the production of IFN-gamma (Fig. 2A), IL-2 (Fig. 2B), IL-4 (Fig. 2C), and MIP-2 (Fig. 2D) by $41 \%, 31 \%, 39 \%$, and $145 \%$, respectively, when compared with uninfected VIP-untreated mice. In VIP-treated mice, infection with $T$. cruzi increased the production of IFN-gamma (Fig. 2A), IL-4 (Fig. 2C), and MIP-2 (Fig. 2D) by 44\%, 124\%, and $284 \%$, respectively, when compared with uninfected VIP-treated mice. Compared with $T$. cruzi infected untreated group, administration of VIP in T. cruzi-infected mice led to a decrease in serum concentrations of IFN-gamma (Fig. 2A) and IL-2 (Fig. 2B) by $14 \%$ and $39 \%$, respectively. Conversely, VIP treatment increased the expression of IL- 4 by $22 \%$ compared with $T$. cruzi infected untreated mice (Fig. 2C). MIP-2 expression was not affected by VIP administration (Fig. 2D). The administration of VIP or its vehicle in uninfected mice did not modify the expression profiles of IFN-gamma, IL-2, IL-4, or MIP-2 (Fig. 2). The balance between proinflammatory and antiinflammatory cytokine production is essential to parasitemia and inflammation control in Chagas disease. We analyzed cytokine ratios and observed a decrease in the ratio between the expression of IFN-gamma and that of the Th2 cytokine IL-4 $(1.9 \pm 0.2)$ in T. cruziinfected VIP-treated mice compared with uninfected VIP-treated mice $(2.7 \pm 0.3)$ (Fig. $2 \mathrm{E}$ ). A similar result was observed in the IL-

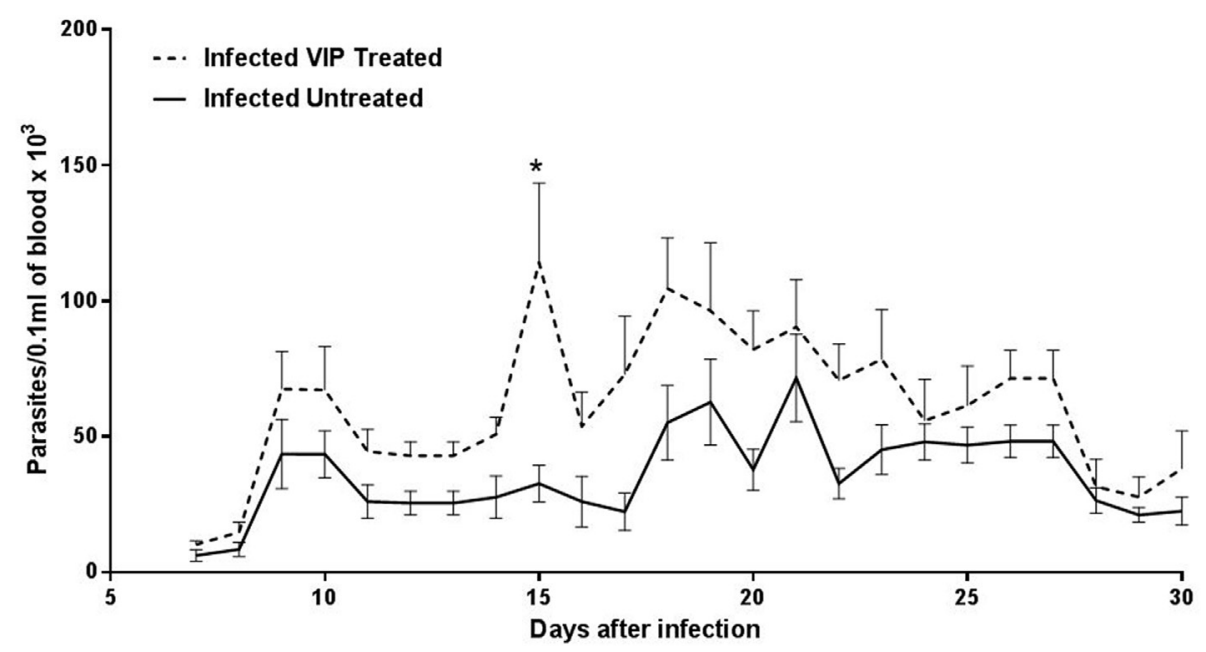

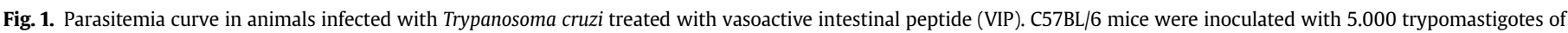

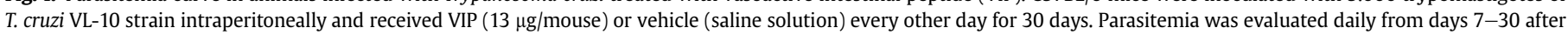
infection. Values are presented as the means of ten mice. Significant differences between groups are shown as ${ }^{*}, \mathrm{P}<0.05$. 
2/IL-4 ratio in infected VIP-treated mice $(1 \pm 0.1)$ compared with uninfected VIP-treated mice $(2.4 \pm 0.4)$ (Fig. $2 \mathrm{~F}$ ). On comparison of IFN-gamma/IL-4 and IL-2/IL-4 ratios in the infected VIP-untreated and infected VIP-treated groups, we observed that VIP treatment decreased IFN-gamma/IL-4 (1.9 \pm 0.2 vs. $2.6 \pm 0.1)$ and IL-2/IL-4 $(1 \pm 0.1$ vs. $2 \pm 0.3$ ) (Fig. $2 \mathrm{E}$ and F). In control VIP-untreated mice, infection did not alter the cytokine balance (Fig. 2E and F).

Since we observed alterations in systemic immune responses through cytokine expression after VIP administration, we wondered if those alterations were reflected at cardiac sites. Heart mass of infected VIP-treated mice $(4.9 \pm 0.1 \mathrm{mg})$ was significantly decreased compared to infected VIP-untreated mice $(5.5 \pm 0.12 \mathrm{mg})$ (Fig. 3A). Histological analysis of the myocardium was performed to determine if heart weight was related to cellular alterations in heart tissue. Cardiac tropism with typical inflammatory reactions to T. cruzi, with vascular and cellular alterations such as hyperemia and hydropic degeneration of cardiac cells, was observed. Additionally, at the end of treatment (30 days after infection), VIPtreated infected animals (Fig. 3B) showed lesser inflammatory infiltrate $(131 \pm 18.5$ cells $)$ than did the VIP-untreated infected control animals (198 \pm 22.3 cells). The VIP-untreated group presented with intense focal inflammatory infiltrates, while the VIPtreated group presented with more discrete and diffuse inflammatory infiltrates (Fig. 3C-F). We did not observe any amastigote nests in analyzed tissue sections of VIP-treated and untreated mice. Uninfected mice treated with VIP did not present any histopathological alterations in the heart (data not shown). Our results indicate that VIP affects the hearts of mice infected with $T$. cruzi by decreasing immune cell proliferation and myocardial infiltration.

\section{Discussion}

The inflammatory response generated after $T$. cruzi infection is an important factor in the control of parasitemia in the acute phase and the development of the chronic phase of human and experimental Chagas disease (Lannes-Vieira et al., 2009; Talvani and Teixeira, 2011). However, the persistence of inflammation may lead to the development of lesions in host organs since the immune
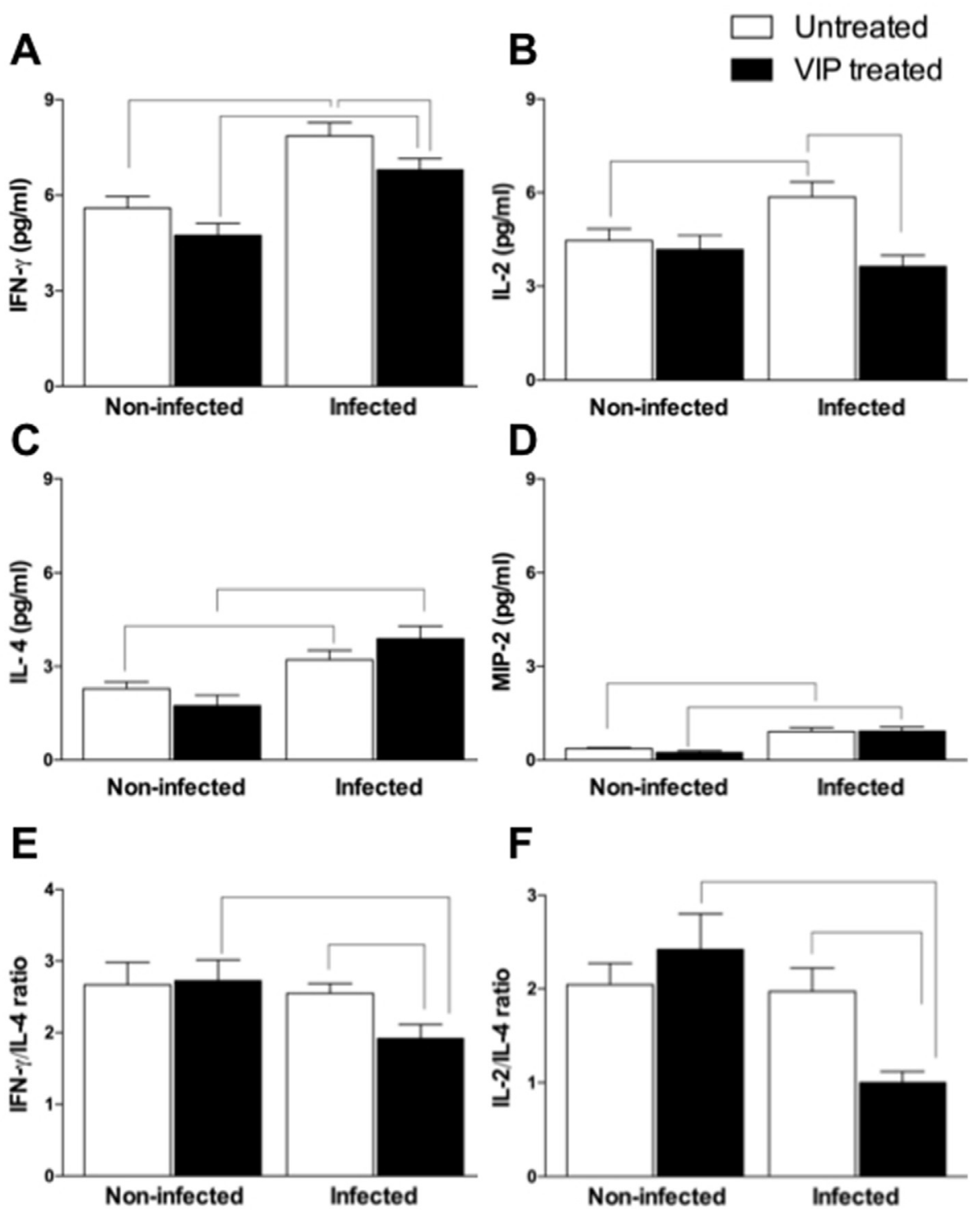

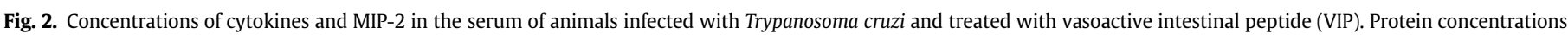

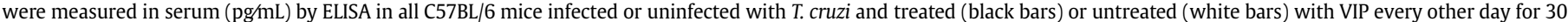

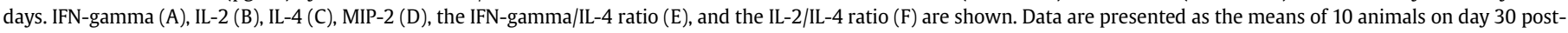
infection. Significant differences $(\mathrm{p}<0.05)$ between groups are indicated by connecting lines. 
A

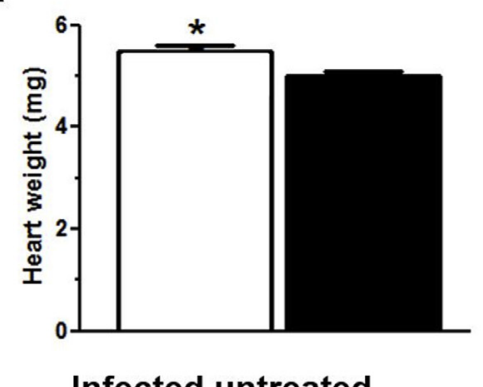

Infected untreated

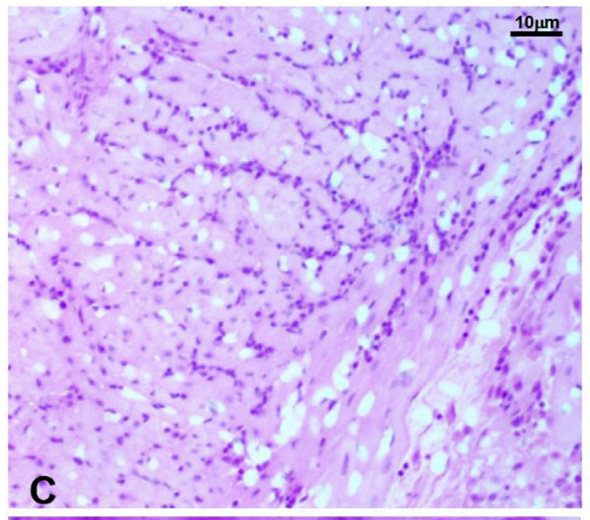

B 口 untreated

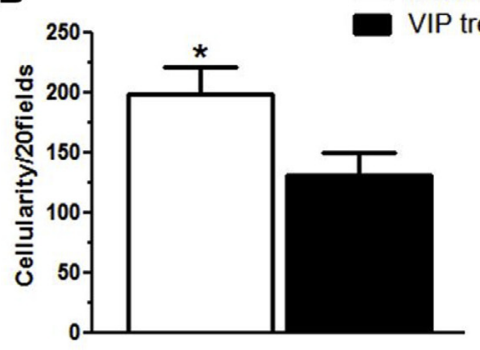

Infected VIP treated

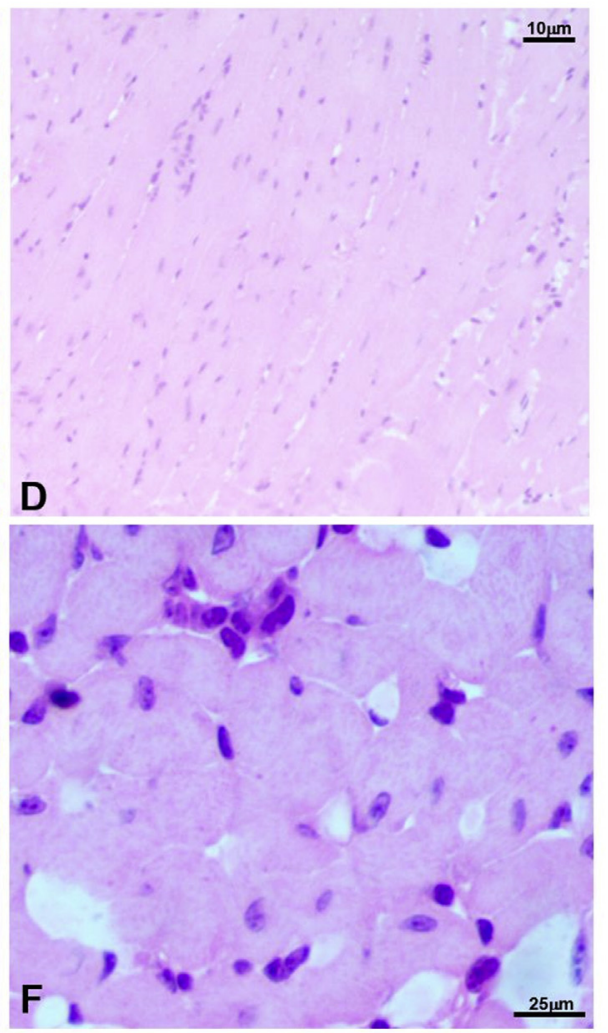

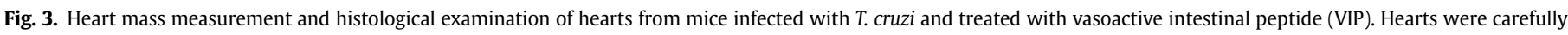

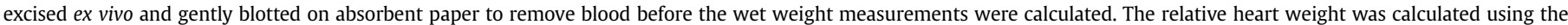

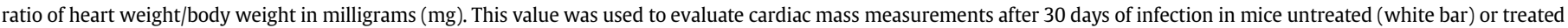

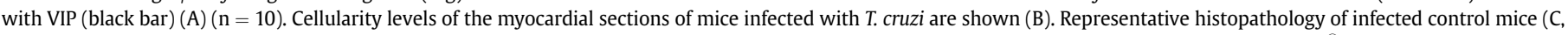

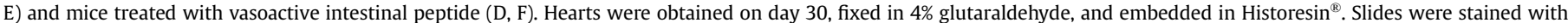
$\mathrm{H} \& \mathrm{E}$. Images are representative of at least three mice in each group. * indicates $\mathrm{P}<0.05$ between groups.

cells recognize and attack host tissues. Because of the possible deleterious effects of immune responses in Chagas disease, studies have been designed to modulate the inflammatory process and its harmful effects to the body by using drugs with anti-inflammatory profiles. The use of anti-inflammatory drugs reduced cardiac inflammatory infiltrates, fibrosis, and circulating cytokines/chemokines and improved cardiac function in T. cruzi infection (Botoni et al., 2007; Coelho Dos Santos et al., 2010; Paula-Costa et al., 2010). The results obtained using anti-inflammatory compounds in Chagas disease motivated the search for new therapeutic targets that are efficient in controlling the inflammatory response observed in Chagas disease patients. Along these lines, vasoactive intestinal peptide (VIP), a neuropeptide endogenously produced in many tissues and organs that is nontoxic and has immunomodulatory activities, is a good candidate as a natural immunomodulatory factor. Additionally, studies have proven the therapeutic potential of VIP in several diseases, especially in inflammatory, respiratory, and neurodegenerative disorders (Campos-Salinas et al., 2014). Furthermore, VIP exerts a direct antimicrobial activity against bacteria (El Karim et al., 2008) and T. brucei (Delgado et al., 2009).

Based on the above-mentioned information, we evaluated the effects of VIP in acute experimental infection with T. cruzi. Our results indicate that VIP did not alter parasitemia during the 30 days of infection. However, VIP shifted the immune response to a Th2 profile, which led to less aggressive myocarditis when compared to infected VIP-untreated mice.

VIP shares similarities with other neuropeptides, such as small size, cationic charge, and amphipathic design. Moreover, VIP is released during microbe-induced inflammation. These findings support a new role for VIP as a potential host defense peptide (Delgado et al., 2009, Delgado and Ganea, 2011). On the other hand, 
VIP is minimally stable after systemic administration, and its poor penetration at the desired site of action could influence its clinical application. In our model of study, VIP was unable to reduce blood parasitemia. In recent work that tested VIP and two analogues in experimental leishmaniasis infection, native VIP did not significantly reduce the viability of promastigote forms of $L$. major and thus failed as a leishmanicidal agent. Although VIP injection diminished paw swelling and lesion size, VIP was not able to significantly control the clinical manifestations and progression of this disease (Campos-Salinas et al., 2014). On the other hand, VIP displayed strong antimicrobial activity against $T$. brucei, causing parasite death by destroying membrane integrity (Gonzalez-Rey et al., 2006). In experimental infection with T. brucei, VIP treatment led to an improvement of symptoms by reducing the parasite burden in many target organs (Delgado et al., 2009). Those results showed that the effects of VIP on trypanosomatid parasites and subsequent infections might vary. Considering these observations, VIP dose adjustment and/or the use of stable VIP analogues could clarify the effects of this neuropeptide on $T$. cruzi viability and confirm if there is a potential antimicrobial role for VIP in T. cruzi in vivo and in vitro models.

In relation to cardiac effects, VIP treatment efficiently reduced the intensity of heart inflammation in animals inoculated with the VL10 T. cruzi strain. This was confirmed by reduction of heart mass and cellular infiltrates in the myocardium of VIP-treated mice compared to infected VIP-untreated animals. VIP exerts its biological activities by binding to the closely related class II G proteincoupled receptors VIP receptor type 1 (VPAC1) and VIP receptor type 2 (VPAC2). Both receptors are coupled to adenylate cyclase activation and subsequent activation of the protein kinase A (PKA) in immune cells. Activation of this pathway leads to the inhibition of transcription factors that upregulate a large number of proinflammatory genes (Smalley et al., 2009). The suppression of heart inflammation by VIP may be, in part, associated with a systemic reduction in cytokines such as IFN-gamma and IL-2 and a concomitant increase in IL-4 production. The protective response against $T$. cruzi infection is influenced by innate and adaptive immunity. These cells produce inflammatory cytokines, which play a central role in regulating parasite replication and immune responses. In addition to the systemic effects of VIP on the immune system, infection increases the levels of IFN-gamma, IL-4, and MIP2. VIP treatment reduced IFN-gamma and IL-2 production and increased IL-4 plasma levels. The modulation of IFN-gamma and IL2 and upregulation of IL-4 observed in infected VIP-treated mice may be important to control cell mediated immunity and tissue damage elicited by $T$. cruzi infection because IL- 4 regulates the development and effector functions of cell-mediated immunity (Talvani et al., 2000). Additionally, cytokines produced by T lymphocytes after T. cruzi infection, such as interleukin 2 (IL-2), trigger important effector mechanisms and act as important growth factors for $\mathrm{CD}^{+}$lymphocyte effector functions (Martin and Tarleton, 2004). Activated $\mathrm{CD}^{+} \mathrm{T}$ cells that express granzyme A are abundant in cardiac tissue from Chagas disease patients, connecting these cells to tissue destruction (Reis et al., 1993). The reduction in IL-2 production may lead to a reduction of activated $\mathrm{CD}^{+} \mathrm{T}$ cells and less heart damage. Studies show that production of proinflammatory cytokines, such as IFN-gamma and TNF-alpha, plays a pathogenic role in T. cruzi-induced cardiomyopathy, and the deleterious effects of these factors have already been reported in experimental models and in human disease (Cunha-Neto et al., 2009; Terasaki et al., 2008; Reifenberg et al., 2007). On the other hand, IFN-gamma production is essential for parasite elimination since this cytokine activates macrophages, which are thought to be a major cell population involved in parasite uptake through the production of several intracellular killing mediators such as nitric oxide (Borges et al., 2013). In our model, the reduced of IFN-gamma production did not affect parasitemia, which was similar between VIP-treated and untreated mice. Therefore, the reduction in IFNgamma production due to VIP treatment may limit cardiac damage without resulting in increased parasitemia. Given this, although treatment with vasoactive intestinal peptide did not prevent cardiac inflammation triggered by infection with Trypanosoma cruzi, the inflammation observed in infected VIP-treated mice was limited compared to that in VIP-untreated mice.

Histological analyses did not reveal amastigote nests in the cardiac tissue of infected mice either treated or untreated with VIP. Theories of parasite persistence and autoreactivity explain the establishment of Chagas disease (Dutra et al., 2009). Our understanding is that parasite presence is required to trigger an immune response, which can control parasitemia in the transition period between acute and chronic phases of the disease. The immune response sustained by the host after attaining the chronic phase will determine the pathological manifestations of the disease. Thus, the inflammatory response is fundamental for parasite control in the early stages of infection, and the modulation of this immune response is essential to avoid an exacerbation of this response and the resulting tissue damage. Supporting this, VIP participates in the modulation of immune response.

Regarding human Chagas disease, data from our group show that patients with Chagas disease with cardiac disorders present lower plasma levels of VIP compared to those in individuals with the indeterminate form of the disease. This suggests that higher or lower VIP expression may be related to the maintenance of the indeterminate form or to the development of the cardiac disorders, respectively (Corrêa et al., 2013). Altogether, results from the human study and this work suggest a protective role of VIP in cardiac tissue after $T$. cruzi infection. Future studies may indicate beneficial effects of VIP mediated immunomodulation, allowing for the creation of new treatment strategies and therapeutics to improve the quality of life of patients with Chagas disease.

\section{Acknowledgments}

This work was supported by Pró-Reitoria de Pesquisa da UFMG (PRPQ/UFMG) and by grants from the Fundação de Amparo à Pesquisa do Estado de Minas Gerais and Conselho Nacional de Desenvolvimento Científico e Tecnológico (PRONEX-Chagas/ Demanda Universal - FAPEMIG and CNPq). We thank Dr. Luis Carlos Crocco Afonso (NUPEBUFOP) for support with the C57BL/6 mice used in this work.

\section{References}

Allam, G., 2007. Vasoactive intestinal peptide inhibits liver pathology in acute murine schistosomiasis mansoni and modulates IL-10, IL-12 and TNF-alpha production. Immunobiology 212 (8), 603-612 (Epub).

Anderson, P., Gonzalez-Rey, E., 2010. Vasoactive intestinal peptide induces cell cycle arrest and regulatory functions in human T cells at multiple. Mol. Cell Biol. 30 (10), 2537-2551.

Borges, D.C., Araújo, N.M., Cardose, C.R., Lazo Chica, J.E., 2013 Feb. Different parasite inocula determine the modulation of the immune response and outcome of experimental Trypanosoma cruzi infection. Immunology 138 (2), 145-156.

Botoni, F.A., Poole-Wilson, P.A., Ribeiro, A.L., Okonko, D.O., Oliveira, B.M., Pinto, A.S., Teixeira, M.M., Teixeira, A.L.J.R., Reis, A.M., Dantas, J.B., Ferreira, C.S., Tavares, W.C.J.R., Rocha, M.O., 2007. A randomized trial of carvedilol after reninangiotensin system inhibition in chronic Chagas cardiomyopathy. Am. Heart J. 153, e1-8.

Brener, Z., 1962. Therapeutic activity and criterion of cure on mice experimentally infected with Trypanosoma cruzi. Rev. Inst. Med. Trop. Sao Paulo 4, 389-396.

Caldas, I.S., Talvani, A., Caldas, S., Carneiro, C.M., DE, L.M., Da Matta Guedes, P.M., Bahia, M.T., 2008. Benznidazole therapy during acute phase of Chagas disease reduces parasite load but does not prevent chronic cardiac lesions. Parasitol. Res. 103, 413-421.

Campos-Salinas, J., Cavazzuti, A., O'valle, F., Forte-Lago, I., Caro, M., Beverley, S.M., Delgado, M., Gonzalez-Rey, E., 2014. Therapeutic efficacy of stable analogues of 
vasoactive intestinal peptide against pathogens. J. Biol. Chem. 289 (21), $14583-14599$.

Coelho Dos Santos, J.S., Menezes, C.A., Villani, F.N., Magalhães, L.M., Scharfstein, J., Gollob, K.J., Dutra, W.O., 2010. Captopril increases the intensity of monocyte infection by Trypanosoma cruzi and induces human T helper type 17 cells. Clin. Exp. Immunol. 163, 528-536.

Corrêa, M.V., Da Costa Rocha, M.O., De Sousa, G.R., Do Carmo Pereira Nunes, M., Gollob, K.J., Dutra, W.O., Da Silva Menezes, C.A., 2013. Low levels of vasoactive intestinal peptide are associated with Chagas disease cardiomyopathy. Hum. Immunol. 74 (10), 1375-1381.

Cunha-Neto, E., Nogueira, L.G., Teixeira, P.C., Ramasawmy, R., Drigo, S.A., Goldberg, A.C., Fonseca, S.G., Bilate, A.M., Kalil, J., 2009. Immunological and nonimmunological effects of cytokines and chemokines in the pathogenesis of chronic Chagas disease cardiomyopathy. Mem. Inst. Oswaldo Cruz 104 (Suppl. I), 252-258.

De La Fuente, M., Delgado, M., Gomariz, R.P., 1996. VIP modulation of immune cell functions. Adv. Neuroimmunol. 6, 75-91.

Delgado, M., Anderson, P., Garcia-Salcedo, J.A., Caro, M., Gonzalez-Rey, E., 2009. Neuropeptides kill African trypanosomes by targeting intracellular compartments and inducing autophagic-like cell death. Cell Death Differ. 16 (3), 406-416.

Delgado, M., Ganea, D., 2011. Vasoactive intestinal peptide: a neuropeptide with pleiotropic immune functions. Amino Acids 3, 4-5.

Delgado, M., Munoz-Elias, E.J., Gomariz, R.J., Ganea, D., 1999. Vasoactive intestinal peptide and pituitary adenylate cyclase-activating polypeptide enhance IL-10 production by murine macrophages: in vitro and in vivo studies. J. Immunol. $162,1707-1716$

Delgado, M., Munoz-Elias, E.J., Gomariz, R.J., Ganea, D., 1996. Vasoactive intestinal peptide and pituitary adenylate cyclase-activating polypeptide prevent inducible nitric oxide synthase transcription in macrophages by inhibiting NF-kB and IFN regulatory factor 1 activation. J. Immunol. 162 (8), 4685-4696.

Dutra, W.O., Menezes, C.A., Magahães, L.M., Gollob, K.J., 2014. Immunoregulatory networks in human Chagas disease. Parasite Immunol. 36 (8), 377-387.

Dutra, W.O., Menezes, C.A., Villani, F.N., Da Costa, G.C., Da Silveira, A.B., Reis, D.D., Gollob, K.J., 2009. Cellular and genetic mechanisms involved in the generation of protective and pathogenic immune responses in human Chagas disease. Mem. Inst. Oswaldo Cruz 104 (Suppl. 1), 208-218.

El Karim, I.A., Linden, G.J., Orr, D.F., Lundy, F.T., 2008. Antimicrobial activity of neuropeptides against a range of micro-organisms from skin, oral, respiratory and gastrointestinal tract sites. J. Neuroimmunol. 200, 11-16.

Gomariz, R.P., Arranz, A., Abad, C., Torroba, M., Martinez, C., Rosignoli, F., GarciaGómez, M. Leceta, J., Juarranz, Y., 2005. Time-course expression of Toll-like receptors 2 and 4 in inflammatory bowel disease and homeostatic effect of VIP. J. Leukoc. Biol. 78, 491-502.

Gonzalez-Rey, E., Chorny, A., Delgado, M.V.I.P., 2006. An agent with license to kill infective parasites. Ann. N. Y. Acad. Sci. 1070, 303-308.
Igarashi, H., Fujimori, N., Ito, T., Nakamura, T., Oono, T., Nakamura, K., Suzuki, K., Jensen, R.T., Takayanagi, R., 2011. Vasoactive intestinal peptide (VIP) and VIP receptors: elucidation of structure and function for therapeutic applications. IJCM 2, 500-508.

Lannes-Vieira, J., Silverio, J.C., Pereira, I.R., Vinagre, N.F., Carvalho, C.M.E., Paiva, C.N. Silva, A.A., 2009. Chronic Trypanosoma cruzi-elicited cardiomyopathy: from the discovery to the proposal of rational therapeutic interventions targeting cell adhesion molecules and chemokines receptors - how to make a dream come true. Mem. Inst. Oswaldo Cruz 104 (Suppl. I), 226-235.

Martin, D., Tarleton, R., 2004. Generation, specificity, and function of CD8 ${ }^{+}$T cells in Trypanosoma cruzi infection. Immunol. Rev. 201, 304-331.

Paula-Costa, G., Silva, R.R., Pedrosa, M.C., Pinho, V., De Lima, W.G., Teixeira, M.M. Bahia, M.T., Talvani, A., 2010. Enalapril prevents cardiac immune-mediated damage and exerts anti-Trypanosoma cruzi activity during acute phase of experimental Chagas disease. Parasite Immunol. 32, 202-208.

Pozo, D., Gonzalez-Rey, E., Chorny, A., Anderson, P., Varela, N., Delgado, M., 2007. Tuning immune tolerance with vasoactive intestinal peptide: a new therapeutic approach for immune disorders. Peptides 28 (9), 1833-1846.

Reifenberg, K., Lehr, H.A., Torzewski, M., Steige, G., Wiese, E., Küpper, I., Becker, C., Ott, S., Nusser, P. Yamamura, K., Rechtsteiner, G., Warger, T., Pautz, A Kleinert, H., Schmidt, A., Pieske, B., Wenzel, P., Münzel, T., Löhler, J., 2007 Interferon-gamma induces chronic active myocarditis and cardiomyopathy in transgenic mice. Am. J. Pathol. 171 (2), 463-472.

Reis, D.D., Jones, E.M., Tostes, S.J.R., Lopes, E.R., Gazzinelli, G., Colley, D.G. McCurley, T.L., 1993. Characterization of inflammatory infiltrates in chronic chagasic myocardial lesions: presence of tumor necrosis factor-alpha ${ }^{+}$cells and dominance of granzyme $\mathrm{A}^{+}, \mathrm{CD}^{+}$lymphocytes. Am. J. Trop. Med. Hyg. 48, 637-644.

Smalley, S.G., Barrow, P.A., Foster, N., 2009. Immunomodulation of innate immune responses by vasoactive intestinal peptide (VIP): its therapeutic potential in inflammatory disease. Clin. Exp. Immunol. 157 (2), 225-234.

Talvani, A., Teixeira, M.M., 2011. Inflammation and Chagas disease: some mechanisms and relevance. Adv. Parasitol. 76, 171-194.

Talvani, A.L., Ribeiro, C.S., Aliberti, J.C., Michailowsky, V., Santos, P.V., Murta, S.M., Romanha, A.J., Almeida, I.C., Farber, J., Lannes-Vieira, J., Silva, J.S., Gazzinelli, R.T., 2000. Kinetics of cytokine gene expression in experimental chagasic cardiomyopathy: tissue parasitism and endogenous IFN-gamma as important determinants of chemokine mRNA expression during infection with Trypanosoma cruzi. Microbes Infect. 2 (8), 851-866.

Terasaki, F., Ukimura, A., Tsukada, B., Fujita, S., Katashima, T., Otsuka, K., Otsuka, K. Kanzaki, Y., Shimomura, H., Fujita, M. Tanaka, T., Kitaura, Y., 2008, Enhanced expression of type 1 helper T-cell cytokines in the myocardium of active cardiac sarcoidosis. Circ. J. 72 (8), 1303-1307.

World Health Organization, 2012. Chagas' disease (American trypanosomiasis) fact sheet (revised in August 2012). Wkly. Epidemiol. Rec. 87, 519-522. 